\title{
ESCRITURAS FEMENINAS DE SU VIDA (FRANCIA, SIGLOS XVI-XVIII)
}

\author{
WOMEN'S WRITING OF HER LIFE \\ (FRANCE, XVI-XVIII CENTURIES)
}

\author{
Sylvie Mouysset \\ Université Toulouse - Jean Jaurès \\ mouysset@univ-tlse2.fr
}

Resumen: En 1987, Michelle Perrot mencionó la escasa presencia de mujeres en nuestros archivos públicos y privados: «En el teatro de la memoria, las mujeres son una ligera sombra». Hoy, gracias al importante trabajo realizado recientemente por los historiadores sobre el inventario de los escritos personales, se ha reevaluado afortunadamente la estimación de la toma de la pluma por parte de las mujeres. Su escritura es notable por la extrema hibridación de sus medios y contenidos, desde el papel olvidado sobre una mesa hasta el diario íntimo más grueso.

En la medida de lo posible, observaremos aquí a todas las mujeres, incluso a las más discretas escritoras sin calidad que solo han dejado una frágil huella de sus minúsculas vidas.

En primer lugar, mencionaremos la diversidad de sus escritos y observaremos que las mujeres no se privan de ningún modo de expresión, aunque su presencia sea rara en algunos casos. A continuación, nos centraremos con mayor precisión en lo que hace que su escritura sea tan especial. Al hacerlo, observaremos que un bosque de escritoras probablemente sigue escondido en nuestros archivos y merece ser descubierto.

Palabras clave: escritos personales, autobiografía, memoria, mujeres, historia de género.

Abstract: In 1987, Michelle Perrot mentioned the low presence of women in our public and private archives: «In the theatre of memory, women are light shadows».

Today, thanks to the important work done recently by historians to inventory personal writings, the estimate of female pen-taking has fortunately been reassessed. Women's writing is highly hybrid, from the media to the content, from the forgotten paper on a table to the thickest diary. As far as possible, we will observe here all women, even the most discreet, writers without quality who have left only a fragile trace of their tiny lives. 
Sylvie Mouysset

Escrituras femeninas de su vida (Francia, siglos XVI-XVIII)

We will first mention the diversity of their writings and observe that women do not forbid themselves any mode of expression, even if their presence is rare in some cases. We will then focus more precisely on what makes their writing so special. In doing so, we will observe that a forest of female writers is probably still hiding in our archives and deserves to be discovered.

Keywords: personal writings, autobiography, memory, women, gender history.

es es es

En 1987, Michelle Perrot mencionó la escasa presencia de mujeres en nuestros archivos públicos y privados: «En el teatro de la memoria, las mujeres son una ligera sombra» (Perrot 1998: 19). Esta ligereza ha sido confirmada varias veces, particularmente debido al escaso número de escritos femeninos identificados para la Edad Moderna. En efecto, los hombres han dejado a las mujeres un lugar ínfimo y mesurado tanto en el mantenimiento de la contabilidad del hogar como en la redacción más elaborada de memorias y diarios íntimos, ya que las mujeres no colaboran de manera tan sistemática, regular y duradera en el trabajo de memoria de la familia.

Hoy, gracias al importante trabajo realizado recientemente por los historiadores en Europa y en Estados Unidos sobre el inventario de los escritos personales, se ha reevaluado afortunadamente la estimación de la toma de la pluma por parte de las mujeres. Esta memoria se recupera gracias al cuidado meticuloso de investigadores que han descubierto, clasificado y puesto a disposición de la comunidad científica miles de referencias documentales con paciencia. ${ }^{1}$ Producidos fuera de las instituciones, en el marco de la esfera individual y privada, estos textos se presentan en una amplia variedad de formas y formatos: periódicos, memorias, correspondencia, libros de amistad, pero también aquí se recogen registros de cuentas y documentos familiares, sin olvidar las hojas sueltas que contienen recetas, largas listas de remedios...

Debemos subrayar la extrema hibridez de los soportes y de los contenidos, que abrazan desde el papel olvidado sobre una mesa hasta el diario íntimo más grueso. Nos centraremos aquí en la profusión de los modos de expresión más ordinarios elegidos por las mujeres — sencillos o complejos, desde el texto hasta el collage o el bordado- y, por tanto, en la diversidad de sus huellas escritas. La escritura de

I. Para Francia, la base de datos del grupo de investigación Les écrits du for privé en France de la fin du Moyen Age à 19I4, es un poco antigua: <http://ecritsduforprive.huma-num.fr/>. Una base de datos más reciente, la de Suiza: <http://wp.unil.ch/egodocuments>. Para Cataluńa y el resto de territorios del ámbito lingüístico catalán, puede consultarse la base de datos Memòria Personal: <http://www.memoriapersonal.eu>. 
las mujeres, más que ninguna otra, es el lugar de las diferencias, empezando por su acceso desigual a la cultura escrita. La narración de su vida cotidiana solo es posible, obviamente, en la mayoría de los casos referidos, con la condición mínima de saber escribir. Y aquí encontramos el verdadero obstáculo, porque solo un poco más del IO\% de las mujeres pusieron su nombre en el fondo de un registro notarial a finales del siglo XVII; quizás el doble en la época de la Revolución. De hecho, las mujeres aquí reunidas no pertenecen a la gente común; son al menos hijas o esposas de maestros artesanos, abogados o médicos, comerciantes y artesanos, todos ellos familiarizados con el registro escrito de sus hechos y milagros profesionales y familiares. Y en la mayoría de los casos, pertenecen a los niveles más altos de la élite burguesa o nobiliaria. En la medida de lo posible, aquí tomaremos en consideración a todas las mujeres, incluso a las más discretas, escritoras sin calidad que solo han dejado una frágil huella de sus minúsculas vidas.

No es necesario dominar la lengua de Montaigne o Voltaire para llevar un registro doméstico. De hecho, tan solo unos pocos elementos básicos son suficientes para tomar la pluma y verter tu vida ordinaria en una hoja de papel en blanco. La escritura es, por supuesto, para las mujeres que conocen sus principios esenciales, un medio fuerte de empoderamiento familiar y social, así como un poderoso instrumento de acción, ya que su capacidad de actuar o agency está estrechamente ligada al registro individual de sus actividades a largo plazo.

El segundo rasgo característico de estos escritos, además de su extrema variedad, es el modo discontinuo de escritura femenina. Fragmentos, hojas sueltas, participación irregular en el libro de familia como relevo entre dos hombres; las palabras de las mujeres son inestables, rápidas, torpes, efímeras, casi ilegítimas en el marco de una delegación de redacción a corto plazo. Esta singular temporalidad ha justificado durante mucho tiempo, a ojos de los especialistas, el escaso número de las huellas escritas que nos han dejado en la Edad Moderna. En los últimos años, sin embargo, el trabajo de jóvenes historiadores ha puesto en tela de juicio la relativa rareza de los escritos de las mujeres. Al solicitar fondos privados que nunca se habían utilizado, al explorar los inmensos fondos de correspondencia intercambiados entre miembros de la familia o con ciertos médicos, al examinar todos los rastros de la escritura doméstica, las mujeres parecen hoy menos fantasmales de lo que eran en el momento en que Michelle Perrot las imaginaba en forma de «ligeras sombras».

En primer lugar, mencionaremos la diversidad de sus escritos y observaremos que las mujeres no se privan de ningún modo de expresión, aunque su presencia sea rara en algunos casos. A continuación, nos centraremos con mayor precisión en lo que hace que su escritura sea tan especial. Al hacerlo, observaremos que un bosque de 
Sylvie Mouysset

Escrituras femeninas de su vida (Francia, siglos XVI-XVIII)

escritoras probablemente sigue escondido en nuestros archivos y merece ser descubierto, como lo han sido recientemente Henriette de Marans (Chollet 20I6), Marie-Caroline de Naples (Chatenet-Calyste 2013) y Marie-Fortunée d'Este (Traversier 2017), todas, a la vez, autoras y actrices de sus propias vidas.

\section{DEL LIBRO DE CUENTAS A LAS MEMORIAS: UNA PRESENCIA FEME- NINA DESIGUAL}

Tanto los libros de contabilidad, como documentos familiares, correspondencia, libros de amigos (alba amicorum), hojas sueltas, pero también memorias y diarios, son todos medios disponibles en los tiempos modernos para contar la historia de su vida. Cualquiera que sea el medio elegido, las mujeres no se apropian de estos medios de expresión de la misma manera que los hombres. La razón más obvia de esta desigualdad de acceso al mundo escrito es que las mujeres tienen menos control sobre las técnicas de escritura. La baja tasa de alfabetización de las niñas, tanto en Francia como en otros países, es la causa principal de esta situación de inferioridad, ya que la lectura y la escritura no están en la cúspide de su aprendizaje. A finales del siglo XVII, solo el I4\% de las mujeres francesas sabía firmar su contrato de matrimonio, frente al 29\% de los franceses (Furet 1977, Chartier 1976). Además, incluso cuando han aprendido a leer y escribir, estos conocimientos no son realmente necesarios en su vida diaria; en otras palabras, no hay necesidad de saber leer o escribir para dirigir correctamente un hogar.

No es la esposa sino el cabeza de familia quien se encarga de la gestión de las cuentas domésticas y, por lo tanto, es el único responsable de llevar el «libro de cuenta y razón». Libro pequeño o de registro extenso, el «libro de cuenta y razón» es un libro de cuentas (la 'razón' se refiere a la «proporción» latina que significa cálculo), actualizado regularmente por la persona que ejerce la autoridad familiar y que tiene el poder de transmitir los bienes materiales e inmateriales de su linaje. Los elementos seleccionados por el escritor para salvaguardar la memoria del grupo pertenecen al curso ordinario de la vida: acontecimientos familiares, nacimientos, matrimonios, defunciones, compras, ventas, anualidades, recibos, etc. Cuando su pluma es más elocuente y desea anotar en su cuaderno ciertos hechos notables, se puede leer en él las algaradas de determinados soldados o el avistamiento de cometas, la entrada de un gran personaje en algunas ciudades, o las consecuencias de la última epidemia de peste. Además, listas de recetas para tratamientos de hombres y animales, copias de citas literarias o jurídicas, referencias a la historia nacional o, más raramente, internacional, 
enriquecen a veces la historia familiar escrita por cualquier hombre que desee dejar un rastro duradero de su propia vida, de la de sus familiares y de la historia, pequeña y grande, de la que ha sido testigo.

El período de desarrollo de este tipo de escritura ordinaria es posterior al de los libros de familia italianos. Las fechas de los primeros documentos identificados son de finales del siglo XIv. El apogeo de la práctica de este tipo de escritura se produce entre I550 y I650, y luego disminuye y desaparece bastante tarde, en el siglo XX.

En casi todos los casos, casi nueve de cada diez veces, el yo es masculino (Mouysset 2007: I2O): «Le parole son femine et fatti son maschi», dice un proverbio toscano del siglo XV (Klapisch-Zuber 1990: II). La memoria familiar es, por lo tanto, un asunto de hombres, como dice muy claramente Gilbert de Raymond, un noble de Agen del siglo XVIII (Tholin I880: 33 ): ${ }^{2}$

\begin{abstract}
Ce livre, mon fils, n'est fait que pour vous donner une connoissance des affaires de la famille qui ont passé par mes mains pendant ma vie, de la dépense que j'ay fait despuis que je perdis mon père, en $\mathbf{7 5 3}$, des réparations que j'ay fait aux biens que j'ay entretenû le mieux qu'il m'a été possible, de la genealogie de la maison qu'il ne m'a été possible de retrouver, quelques recherches que j'ay pû faire, enfin de tout ce qui peut vous interesser ; car il est bon que vous soyez instruit de ces choses la qui vous seront utiles dans la suite, au cas qu'il vous survienne quelque affaire dont je eû connoissance.
\end{abstract}

El hilo de la memoria masculina se mantiene de padre a hijo y solo se rompe por la muerte o ausencia temporal del padre de familia. Si muere antes de que su hijo alcance la edad adulta, su esposa viuda toma el control y lleva las cuentas, entre el difunto marido y el hijo demasiado joven para escribir. Inserta los avisos necesarios para almacenar los hechos principales en una escritura mediana entre dos hombres. Así, las mujeres están casi excluidas del deber de memoria, salvo en algunas situaciones especiales, como la viudez, la soltería o ante un marido temporalmente ausente. Una joven que permanece soltera escribe su libro de cuentas excepcionalmente, porque la mayoría de las veces permanece bajo la dominación de su padre, o de un hermano mayor, o incluso la de su amo, si ha sido colocada como criada. El caso de la esposa que se encuentra temporalmente sola y obligada a llevar sus cuentas es relativamente frecuente. Siendo su marido convocado a viajar para arreglar sus asuntos o invitado

2. «Este libro, hijo mío, está hecho solo para darte un conocimiento de los asuntos de la familia que han pasado por mis manos a lo largo de mi vida, de los gastos que hice desde que perdí a mi padre en I753, de las reparaciones que hice en la propiedad que mantuve lo mejor que pude, de la genealogía de la casa que pude encontrar, de algunas investigaciones que pude hacer, en fin de todo lo que puede interesarte; porque es bueno que te instruyas de estas cosas que te serán útiles en el futuro, en caso de que se te presente algún asunto del que yo fuera consciente» [traducción de la autora, de aquí en adelante].

Caplletra 67 (Tardor, 2019), p. 171-186 
Sylvie Mouysset

Escrituras femeninas de su vida (Francia, siglos XVI-XVIII)

a servir al rey en sus ejércitos, se le confían entonces a ella las llaves de la casa: ella se encarga de los asuntos de la pareja con cuidado y los registra concienzudamente en el libro de familia.

En ausencia de sus maridos, las mujeres que teóricamente nunca han participado en un asunto muestran un perfecto dominio del tema, lo que prueba que nunca han estado lejos de él. Sin embargo, abandonan sus responsabilidades como administradoras de las cuentas familiares tan pronto como el cabeza de familia regresa a casa. A veces lo hacen con pesar, como Madame de Rochefort, cuyo castillo está cerca de Saint-Rémy de Provence, que admite estar muy preocupada por devolver el libro de cuentas a su marido. Teme que vuelva a malgastar la fortuna familiar, cuyas cuentas acaba de equilibrar, y concluye su confesión con estas palabras: «La melancolía no es buena ni para el cuerpo ni para el alma» (Ribbe I890: 390).

Si las mujeres solo intervienen discretamente $y$, a menudo discontinuamente, en la gestión de las cuentas familiares, participan, directa o indirectamente, en la gestión de los asuntos domésticos. Además, van adoptando gradualmente otros modos de auto-escritura, menos comunes que los libros de cuenta e incluso reservados para una élite educada.

En el siglo Xvi había pocos autores de memorialística con nombre de mujer. Juana de Albret (I528-I572) y Margarita de Valois (I553-I6I5), madre y primera esposa, respectivamente, del futuro Enrique IV, fueron pioneras en este campo. Poco después, a mediados del siglo XVII, Madame de la Guette (1982: 47) constató la escasa presencia de mujeres en este modo de escritura, que requiere un verdadero dominio de la lengua:

Ce n'est pas une chose fort extraordinaire de voir les histoires des hommes qui, par leurs beaux faits ou par leurs vertus éminentes, se sont rendus recommandables à la postérité, ou qui ont été élevés ou abaissés selon les caprices de la fortune; mais il se trouve peu de femmes qui s'avisent de mettre au jour ce qui leur est arrivé dans leur vie. Je serai de ce petit nombre. ${ }^{3}$

Aquí, la historia es siempre más colectiva que privada, más política que íntima. Las mujeres pueden escribir en primera persona, pero no entregan casi nada de su intimidad, con pocas excepciones. Todavía no ha llegado el momento de los grandes derrames románticos; las emociones y los afectos no están claramente expresados. En otras palabras, la identidad revelada por la escritura no es de ninguna manera personal; la memoria es colectiva, familiar o religiosa. En el contexto familiar, algunas autoras

3. «No es muy extraordinario ver las historias de hombres que, por sus buenas acciones o sus eminentes virtudes, se han hecho dignos de elogio para la posteridad, o que han sido elevados o rebajados según los caprichos de la fortuna; pero hay pocas mujeres que se aventuran a revelar lo que les ha sucedido en sus vidas. Seré de este pequeño número». 
compilan archivos familiares y establecen la genealogía de su linaje, esmaltando bautismos, matrimonios y fallecimientos de recuerdos personales de sus familiares: este es el caso de Jeanne du Laurens, hija de un médico en Nîmes (Broomhall \& Winn 2008). Susan Broomhall y Colette Winn trabajaron recientemente sobre dos protestantes francesas del siglo XvI, Charlotte Arbaleste de la Borde y Renée Burlamacchi, quienes dejaron sus memorias (Broomhall \& Winn 2005). Arbaleste fue una de las primeras mujeres en hacerlo. En I584, comenzó a escribir una biografía de su marido, Philippe Duplessis-Mornay, para su hijo. Consciente de las limitaciones de este tipo de escritura, justificó su decisión con el deseo de ofrecer a su hijo un modelo de conducta hugonote. Del mismo modo que los autores de los libros de cuentas, se considera a sí misma como un vínculo esencial entre un padre y su hijo, incluso si ella desaparece voluntariamente frente a estos dos hombres queridos. De su destino personal, comparte lo que ella considera como recuerdos compartidos con su difunto esposo (Broomhall \& Winn 2005: 15):

\section{El sujeto femenino se funde así en la entidad colectiva, de modo que los aspectos públicos (masculinos) y privados (femeninos) ya no son distintos [...]. En resumen, lo público y lo privado son nociones sin sentido que no tienen un significado estable en las memorias de Arbaleste.}

Ella misma cuenta sus embarazos y partos; también da detalles sobre sus enfermedades. Y, si a veces comparte sus sentimientos personales con su lector, siempre lo hace con cautela y preocupación por presentar un aceptable autorretrato de un buen hugonote de la clase noble y de una esposa dedicada a un marido que la respeta y tiene absoluta confianza en ella. De hecho, la biografía que hace de su marido para su hijo es también una oportunidad para que ella exista a través de la escritura. De hecho, menciona varias veces el papel y la influencia que había ejercido realmente junto a Duplessis-Mornay en actividades políticas, religiosas y familiares que compartía ampliamente con él.

Durante los dos siglos siguientes, los recuerdos de las mujeres evolucionaron significativamente con respecto a las historias de los hombres. Después de los problemas de la Fronda, en los que algunas mujeres jugaron un papel importante, su rol público tendió a debilitarse y, de la misma manera, su escritura retrocedió en el ámbito privado y se volvió más personal. Entre la historia y la ficción, las mujeres inventan un nuevo estilo de escritura autobiográfica sin convertirse en autoras. Según Adelaide Cron, que acaba de renovar la historiografía sobre la memoria de las mujeres en Francia en los siglos XVII y XVIII, «también desarrollan nuevas representaciones de la identidad de las mujeres, entre la sumisión y la impugnación, a menudo indirecta, de los papeles femeninos considerados tradicionales en su tiempo» (Cron 20I6). 
Sylvie Mouysset

Escrituras femeninas de su vida (Francia, siglos XVI-XVIII)

Todavía queda mucho por escribir sobre la escritura memorialista de las mujeres durante la Revolución Francesa: los que están en el movimiento, tanto del lado de los patriotas como del de los contrarrevolucionarios, no dudan en escribir diariamente lo que perturba sus vidas, sus esperanzas y sus temores (Petiteau 20I2, Mouysset 20I3). Atraen tanto a figuras domésticas como políticas, con las esferas pública y privada a menudo entrelazadas. Cuando Henriette Campan (1999: 29I-292) describió, por ejemplo, los días de octubre de 1789 , volvió a vivir la escena como si estuviera presente y centró su atención en la reina de la que fue la primera camarera:

\begin{abstract}
Je frémis encore en me souvenant que les poissardes, ou plutôt les furies qui portaient des tabliers blancs, criaient qu’ils étaient destinés à recevoir les entrailles de Marie-Antoinette, qu’elles se feraient des cocardes et mêlaient les expressions les plus obscènes à ces horribles menaces. ${ }^{4}$
\end{abstract}

La escritura femenina de las memorias, como la de los libros de cuentas, es el resultado de una lenta apropiación, desde las primeras décadas de la Edad Moderna, de estilos de escritura concebidos originalmente por y para el hombre. Las mujeres se apoderan de un espacio de escritura masculino y lo modifican para uso propio. Veremos más adelante otro ejemplo de ajuste femenino de un soporte eminentemente masculino, el libro de los amigos.

La apropiación por parte de las mujeres de los medios de escritura inventados por los hombres es, por lo tanto, una constante en la aparición de múltiples escritos femeninos, cuyas especificidades están aún por descubrir.

\title{
2. ESPECIFICIDADES DE LA ESCRITURA FEMENINA COTIDIANA
}

Las mujeres que escriben se enfrentan con mayor frecuencia a la soledad, una condición que resulta de la ausencia de sus maridos, ya sea temporal o permanente. «La soledad es una relación: con el tiempo, con los lugares, con los demás y con uno mismo» (Perrot 1984: 298). Michelle Perrot subraya aquí la importancia de un estado mental y social que no es sinónimo de confinamiento, sino todo lo contrario. Casi siempre efímera, la experiencia de la soledad revela las capacidades de acción de las mujeres para ellas mismas, más aún que para los demás.

Ante el celibato, la partida de sus maridos o la viudez, las mujeres demuestran una impresionante reactividad y una capacidad de adaptación y acción que atesti-

4. «Todavía me estremezco cuando recuerdo que los verduleros, o más bien las furias con delantales blancos, gritaban que estos estaban destinados a recibir las entrañas de María Antonieta, que harían escarapelas con ellas y mezclaban las expresiones más obscenas a estas horribles amenazas». 
guan su familiaridad con la gestión de los asuntos del hogar. Lejos de ser impotentes —o si dicen que lo son, es en realidad una postura de modestia frente a la adversidad-, este reconocimiento de debilidad es momentáneo. Una vez que el choque emocional está bajo control, su compromiso es casi inmediato: no dudan en abrir el libro de familia que normalmente lleva su marido para registrar su voluntad de sobrellevarlo, pase lo que pase (Ribbe I890: 266):

\footnotetext{
Cependant, après avoir donné à la tendresse tout ce qui convenoit, il a fallu songer incessamment à remédier aux accablantes affaires que M. Calvet m'avait laissées, et à payer les dettes considérables qu'il avoit contractées $[\ldots] .^{5}$
}

La toma del poder contable por parte de las mujeres suele ir acompańada, como en este caso, de críticas a la mala gestión de los asuntos del hogar por parte de un marido fallecido que ha dejado tras de sí una situación financiera desastrosa. Bajo la pluma de estas autoras, el descuido y el despilfarro se reducen a lo masculino, mientras que la sabiduría y la precaución definen la forma en que las mujeres hacen negocios en el hogar. Esta propensión a hacer el bien, a demostrar su eficacia en ausencia de sus maridos, es la primera especificidad femenina visible cuando se descubre su participación en el libro de familia.

La preocupación por la eficiencia parece a veces frustrada por el reconocimiento de una verdadera inexperiencia. La torpeza es un hecho objetivo, como lo demuestra la gran libertad ortográfica y el número de manchas de tinta que ensucian la página blanca.

Sin embargo, esta torpeza se asocia al ideal de un cierto pragmatismo femenino: a pesar de que las herramientas intelectuales son inferiores a las de los hombres, las mujeres afirman, por su propensión a hacerse cargo de los asuntos de sus maridos en su ausencia, que lo hacen tan bien como ellos cuando se enfrentan a situaciones complejas. De hecho, no cuentan una historia y casi nunca se imaginan a sí mismo como autoras. Por ejemplo, no adoptan la postura de la persona que escribe con el deseo de ser leída, y por lo tanto de ser publicada: «Je n’ai point voulu faire un livre et n'ai jamais songé à être un auteur» ${ }^{6}$ (Rochejaquelin 1984: 43), admite Madame de la Rochejaquelin (1772-I857) desde el principio de sus memorias. Mucho antes que ella, Margarita de Valois (I553-I6I5) comenzó su autobiografía con palabras que

5. Livre de raison de Marguerite-Mathilde de Cabassole, Villeneuve-les-Avignon, I7I8: «Sin embargo, después de dar ternura a todo lo que era apropiado, era necesario pensar incesantemente en remediar los abrumadores asuntos que el Sr. Calvet me había dejado, y pagar las considerables deudas que había contraído...». 6. «No quería hacer un libro y nunca pensé en ser autor». 
Sylvie Mouysset

Escrituras femeninas de su vida (Francia, siglos XVI-XVIII)

limitaban severamente el campo de acción de esta princesa de alto rango, antigua reina de Francia (Valois I994: II):

Je tracerai mes mémoires, à qui je ne donnerai plus glorieux nom, bien qu’ils méritassent celui d'histoire, pour la vérité qui y est contenue nûment, et sans ornement aucun, ne m’en estimant pas capable... ${ }^{7}$

¿Es realmente sincera? Debemos dudar de ello. Para algunas de estas mujeres de la élite social, la admisión de debilidad no oculta la falsa modestia. La baronesa de Oberkirch (I754-I803) dijo que no podía ir más allá de un simple relato: "Je ne me charge pas d'expliquer ce phénomène, je le raconte, laissant à de plus instruits que moi le soin d'en percer le mystère» (Oberkirch 1989: I69). ${ }^{8}$ Las mujeres, contrariamente a lo que reconocen la mayoría de los hombres, admiten abiertamente que no son buenas para escribir. Pero afirman aún más claramente sus cualidades como dirigentes y, en términos más generales, las de las mujeres de poder que saben cómo imponer sus puntos de vista en la sociedad y su autoridad sobre toda la familia.

Por lo tanto, la escritura es para ellas una forma de existir. Sin embargo, este instrumento de autoafirmación no tiene una continuidad real, sobre todo en lo que se refiere al mantenimiento de los libros de cuentas, en los que las mujeres, que han pasado a ser jefas de hogar durante un tiempo limitado, solo aparecen temporalmente como redactoras de la memoria familiar. La forma fragmentada de su participación en los libros de familia es otra de las características esenciales de la escritura femenina. Esa participación se desarrolla entre dos tomas de escritura masculina, la de su marido y la de su hijo, los únicos que tienen el poder de contar la historia de la familia.

Como las mujeres no han recibido esta delegación de escritura de herencia, practican varias formas de literatura, la mayoría de las veces dedicada a la destrucción, desde hojas sueltas hasta pequeños trozos de papel que se quedan en la esquina de una mesa. Pocas son las que, como Sança Ximenis de Foix i de Cabrera, pertenecen a la nobleza catalana. Casada a los nueve años y viuda joven de Archibal de Foix desde I4I7, lleva con asiduidad su Llibre memorial (Vinyoles 2005). Como muy sabiamente señala Teresa Vinyoles, estas escritoras conservan un cierto gusto por las cosas efímeras, desde recetas de cocina hasta canciones de amor.

7. «Trazaré mis recuerdos, a los que ya no daré un nombre glorioso, aunque merezcan el nombre de la historia, porque la verdad que contiene es desnuda y sin adornos, no me considero capaz...».

8. «No me explico este fenómeno, lo cuento, dejándolo en manos de personas más educadas que yo para que desentrañen su misterio». 


\section{ESCRITOS DE MUJERES, CAMINOS POR RECORRER}

Escribir lo cotidiano, lo colectivo y lo contable, o en un estilo más literario, lo autobiográfico e íntimo, permite a las mujeres adquirir una cierta autonomía, primero en el seno de la familia, pero también en la sociedad en la que viven. Hoy en día se están explorando formas especiales de empoderamiento de la mujer en esferas en las que, al igual que en la gestión de los asuntos domésticos, las normas son establecidas y aplicadas tradicionalmente por los hombres. Nahema Hanafi, por ejemplo, ha demostrado recientemente que la prohibición del acceso al conocimiento académico y científico durante la Ilustración no impidió que las mujeres de la aristocracia europea tomasen posesión de los conocimientos médicos necesarios para cuidar de sus familiares. Para ello, crearon una densa red epistolar - la palabra escrita, por lo tanto, desempeñó también aquí un papel esencial- directamente relacionada con los mejores médicos de su tiempo. La historiadora ha revisado la historia del cuerpo y de la medicina durante la Ilustración. También se ha interesado por la medicalización de la sociedad, basándose en un corpus compuesto esencialmente por escritos personales — correspondencia, memorias y recuerdos, razonamientos y recetarios...y por consultas epistolares enviadas al famoso médico suizo Samuel-Auguste Tissot entre 1765 y 1797 . Esta extensa documentación en forma de biografías médicas le ha permitido trazar las representaciones corporales, la relación con la maternidad y las prácticas de cuidado de las mujeres que vivían en Toulouse, Versalles, París o Lausana. Su riqueza financiera y sus horizontes sociales eran significativamente diferentes, al igual que su edad, religión o número de hijos. Todas ellas pertenecían a la élite de la Ilustración, pero este no era su único punto en común. Sus escritos también dan testimonio de una florecida cultura mundana para mujeres alfabetizadas. Estas fueron testigos de sus propias vidas, a través de la práctica individual de la escritura autobiográfica, y más aún a través de la correspondencia intercambiada con sus amigos, esposos y el resto de la familia, por no hablar de su terapeuta.

Gracias a estos discursos de mujeres y no sobre mujeres, la historiadora ha podido estudiar la recepción de los preceptos médicos en estos ambientes. También ha examinado cuidadosamente ciertas posiciones femeninas, como la negativa a dar a luz y las reflexiones sobre el celibato (¿el rechazo del marido o del hijo?) y, en el contexto del matrimonio, las revelaciones sobre los métodos anticonceptivos, a veces audaces, considerados por las mujeres. Esta joven investigadora finalmente se ha interesado por el autocuidado, por medio de la automedicación o la solicitud de terapeutas de orígenes muy diversos. Ha estudiado, asimismo, las relaciones de poder interfamiliares relacionadas con la gestión del cuidado y, por lo tanto, ha matizado el papel de las mujeres como cuidadoras voluntarias dentro de la familia. 
Sylvie Mouysset

Escrituras femeninas de su vida (Francia, siglos XVI-XVIII)

Nahema Hanafi invita a sus lectores a escuchar el «susurro de los archivos» y a seguir los «itinerarios conformistas o inusuales» de las mujeres cuyos escritos han seguido la pista del poder de la acción en la esfera privada. El análisis detallado del dominio de un cierto conocimiento médico alimentado por lecturas más o menos eruditas, pero también por intercambios epistolares muy ricos, nos permite hoy, gracias a este trabajo pionero, acercarnos mejor a los cuerpos de la Ilustración.

En otro campo, el de la educación, la reciente investigación de Sylvie MoretPétrini ha puesto de relieve la fuerte implicación de las mujeres en la renovación de los métodos y prácticas educativas en la Suiza francófona entre 1750 y 1820, abogando por un equilibrio calculado entre el control estricto y la libertad que podía conducir a un aprendizaje satisfactorio de la vida en sociedad (Moret-Petrini 20I6). La medicina y la educación se refieren definitivamente a los papeles tradicionales asignados a las mujeres en el cuidado de sus familiares en la esfera privada y uno podría pensar, aunque esto no sea cierto, que estas han tenido un acceso más fácil a un cierto grado de autonomía en estas áreas calificadas de preferidas. Estos resultados, muy innovadores en la Suiza francófona, se hacen eco de la investigación realizada en los Países Bajos por Ariane Baggerman \& Rudolf Dekker (2009). El camino abierto solo está a la espera de ser seguido por otros investigadores, en particular franceses, pero también europeos.

Si nos alejamos de la esfera doméstica, otros tipos de fuentes también esperan a las especialistas en literatura femenina. Los alba amicorum o libros de amigos, poco estudiados en Francia, eran soportes reservados originalmente para los estudiantes que estaban haciendo su peregrinatio academica (Losert, Raffel \& Therstappen 2016). A partir del siglo XVI, estos pequeños álbumes blancos comprados a un impresor de libros contenían primero los autógrafos de sus maestros, y luego, poco a poco, los de sus compañeros de estudios a los que confiaban la tarea de escribir una palabra, de colocar su escudo de armas o cualquier otra ilustración de su elección (Mouysset 20I4). La práctica siguió siendo una actividad estudiantil hasta que las jóvenes, a partir del siglo XVIII, se atrevieron a aventurarse en este terreno eminentemente masculino y tomaron posesión de este soporte para darle forma a su manera. Caroline Pfeffel (I769-I8II), hija de un poeta alsaciano, llevaba un libro de amigos. Sus amigos anotaron una palabra, una fórmula, un poema para la hija del venerado poeta, musa de niños y niñas que aquí mezclaban sus impresiones y deseos, compitiendo con citas aprendidas.

El libro de amigos tiene la función especial de ofrecer un retrato heterogéneo de su dueño sin que él/ella haya escrito una sola palabra, o solo en la primera hoja, para escribir su nombre y unas pocas líneas genealógicas. El préstamo del cuaderno es en sí mismo un signo de elección. A cambio, el regalo inspira el contra-regalo: el amigo pone su más bella marca de amistad en homenaje a la persona que lo eligió. 
De hecho, el conjunto es una autobiografía singular escrita por otros para uno mismo. A veces los amigos del cuaderno nunca se han conocido, y su único vínculo es con el destinatario de sus votos amistosos.

Trabajos con agujas, tijeras o cortaplumas, estas meticulosas imágenes, que aparecieron en los libros femeninos del Siglo de las Luces, expresan el afecto mostrado a la amiga, así como también revelan las facetas de un yo escenificado por su séquito. Poemas, citas y fórmulas, dibujos y gouaches, papeles cuidadosamente cortados, pequeños trozos de sí mismo en forma de mechón de pelo, dibujan el ego a lo largo de las páginas, a partir de pequeños objetos reunidos por sus amigos. Aquí podemos imaginar a la poetisa Caroline, enamorada de los grandes espacios, de los hermosos retratos de la ciudad, así como de la sombra de las arboledas o de los placeres del jardín; una mujer culta sin afectación, que aprecia tanto los retruécanos como las bromas de los pequeños Cupidos esparcidos en sus páginas y de los cuales ella misma dibujó el primero en la portada. Los espacios multiplicados del álbum gracias a los numerosos papeles insertados en el corazón de sus páginas ofrecen varias facetas de un yo reflejado por tantos espejos como amigos tiene Caroline.

Los libros de amigos son una forma única e inesperada de escritura personal. ¿Qué hay en común, sin embargo, entre este documento que nos invita a soñar y un libro de cuentas cuya aridez contable a menudo hace huir al investigador principiante? En la superficie, no mucho. Sin embargo, estos textos tan diferentes ofrecen a sus lectores una «biografía coral» para varias voces. Escrito de padre a hijo, en el primer caso, y por amigos del yo, en el segundo, la puesta en escena de uno mismo a partir de estos textos multifacéticos se ve reforzada por la multiplicidad de las tomas de escritura. Estas historias despliegan una visión caleidoscópica del tema, que declina infinitamente la imagen que tenemos de nosotros mismos a través de los ojos de los demás.

\section{CONCLUSIÓN}

Todas estas son pistas que nos permiten imaginar las abundantes obras futuras sobre los escritos femeninos más ordinarios, a largo plazo. Muchas no se han presentado aquí, como los testimonios de mujeres en juicios penales, por ejemplo, o escritos en la cárcel o en un convento. La investigación más reciente es un verdadero motivo de optimismo. Comparto plenamente el entusiasmo de Marina Caffiero por continuar el trabajo de una "memoria restituita» para las mujeres (Caffiero 2007). En Francia, como en Italia, se creyó durante mucho tiempo que eran mudas y que no tenían 
Sylvie Mouysset

Escrituras femeninas de su vida (Francia, siglos XVI-XVIII)

acceso a la escritura simplemente porque no sabían escribir. Hoy, como dijo Daniel Roche sobre los escritos personales, "cuando los buscas, los encuentras». Y Marina Caffiero (2012: I67-I68) añadió:

La quantité abondante et inattendue d'écrits « cachés " de femmes repérés dans les archives romaines démontre, en premier lieu, que l'écriture était loin d'être une pratique rare ou bornée aux seuls milieux aristocratiques [...]. Le deuxième élément [...] est la multiplicité des genres d'écriture, qui vont des lettres aux journaux intimes, des biographies aux autobiographies, des mémoires - de soi, de famille, du groupe d'appartenance -, aux narrations historiques ou aux chroniques. ${ }^{9}$

Los últimos trabajos y las perspectivas de investigación anunciados responden a esta cálida invitación a descubrir los escritos de las mujeres allí donde se encuentren, incluso en los lugares más insólitos, y a dar a conocer estos documentos a través de publicaciones científicas de alta calidad.

Sylvie Mouysset

Université Toulouse - Jean Jaurès mouysset@univ-tlse2.fr

ORCID 0000-0002-6283-0208

\section{REFERENCIAS BIBLIOGRÁFICAS}

Amelang J. (1990) «Los usos de la autobiografía: monjas y beatas en la Cataluña moderna», en J. S. Amelang \& M. Nash (eds.), Historia y género: las mujeres en la Europa Moderna y Contemporánea, Valencia, Edicions Alfons el Magnànim, p. I9I-2I2.

Baggerman A. \& R. DekKer (2009) Child of the Enlightenment: revolutionary Europe reflected in a boyhood diary, Leiden, Brill (Egoducuments and history series, I). Barbeito Carnerio, M. I. (1997) «¿Por qué escribieron las mujeres en el Siglo de Oro?», Cuadernos de Historia Moderna, 19, p. I83-193.

9. «La abundante e inesperada cantidad de escritos ocultos de mujeres encontrados en los archivos romanos muestra, en primer lugar, que la escritura estaba lejos de ser una práctica rara o limitada a los círculos aristocráticos solo [...]. El segundo elemento [...] es la multiplicidad de estilos de escritura, que van desde las cartas hasta los diarios, las biografías, las autobiografías, las memorias -de uno mismo, de la familia, del grupo habitual-, las narraciones históricas o las crónicas». 
Broomhall S. \& C. H. Winn (2005) «La représentation de soi dans les mémoires féminins du début de l'époque moderne», Tangences, 77, p. II-35

- (2008) Les femmes et l'histoire familiale (XVI'-XVIt siècle), París, Champion.

Caffiero, M. (20I2) «Écrire au féminin», Clio. Femmes, Genre, Histoire [online], 35, p. $163-176$.

Caffiero M. \& M. I. Venzo (2007) Scritture di donne. La memoria restituita, Roma, Viella.

Campan, Madame de (I999) Mémoires, París, Mercure de France (Le temps retrouvé).

Castillo Gómez, A. (20I4) «Afectos y disimulos en las cartas privadas de las emigrantes a Indias (siglos XVI y XVII)», en M. L. Candau (ed.), Las mujeres y el honor en la Europa Moderna, Huelva, Universidad de Huelva, p. 30I-3I8.

- (2015) Culturas del escrito en el mundo occidental. Del Renacimiento a la contemporaneidad, Madrid, Casa de Velázquez.

Chartier R., M. M. Compère \& D. Julia (I976) L'éducation en France du XVI au XVIII siècle, París, SEDES.

Chollet, M. (2016) Etre et savoir. Une ambition de ferme au siècle des Lumières, Rennes, PUR (Histoire).

Chatenet-Calyste, A. (2013) Une consommation aristocratique fin de siècle, MarieFortunée d'Este, princesse de Conti (I73I-I803), Presses Universitaires de Limoges.

Cron, A. (20I6) Mémoires féminins de la fin du XVII siècle à la période révolutionnaire: enquête sur la constitution d'un genre et d'une identité, París, Presses de la Sorbonne nouvelle

Furet, F., M. M. Compère \& D. Julia (1977) Lire et écrire, l'alphabétisation des Français de Calvin à Jules Ferry, París, Les éditions de Minuit (Le sens commun).

García Mouton, P. (1996-97) «Las mujeres que escribieron cartas desde América (siglos XVI-XVII)», Anuario de Lingüistica Hispánica, XII, p. 315-326.

Guette, Madame de la (1982) Mémoires écritspar elle-même (I6I3-I676), París, Mercure de France (Le temps retrouvé).

Hanafi, N. (20I7) Le frisson et le baume. Expériences féminines du corps au Siècle des lumières, Rennes et París, PUR-CTHS.

Iuso, A., ed. (1999) Scritture di donne. Uno sguardo europeo, Arezzo, Protagon Editori.

Klapisch-Zuber, C. (1990) La maison et le nom. Stratégies et rituels dans l'Italie de la Renaissance, París, EHESS.

Losert, K., E. Raffel \& A. Therstappen (2016) Alter Ego, Amitiés et réseaux du XVI au XXI siècle, Strasbourg, Bibliothèque nationale universitaire.

Moret-Pétrini, S. (20I6) Pratiques éducatives et écriture du for privé en Suisse romande, I750-I820, Tesis Doctoral de Historia Moderna, supervisada por Danièle TosatoRigo, Université de Lausanne. 
Sylvie Mouysset

Escrituras femeninas de su vida (Francia, siglos XVI-XVIII)

Mouysset S. (2007) Papiers de famille, Introduction à l'étude des livres de raison (France, $X V^{\top}-X I X^{e}$ siècle), Rennes, Presses universitaires de Rennes.

- (2013) «"Silence de mort et craintes extrêmes": la peur en son for privé à l'époque révolutionnaire», Annales historiques de la Révolution française, 373, p. II-34.

—(20I4) «L'amitié reste et jamais ne s'efface. Les alba amicorum: de la marque d'amitié au réseau d'amis ( $\mathrm{xvI}^{\mathrm{e}}-\mathrm{Xx}^{\mathrm{e}}$ siècle)», en M. Daumas (dir.), L'amitié dans les écrits du for privé et les correspondances, de la fin du Moyen Age à IgI4, Pau, PUPPA, p. 6I-78.

Perrot, Michelle (1984) «Posface», en C. Klapisch-Zuber \& A. Farge, Madame ou Mademoiselle ?, París, Montalba.

- (1998) Les femmes ou les silences de l'histoire, París, Flammarion.

Petiteau, N. (20I2) Ecrire la mémoire. Les mémorialistes de la Révolution et de l'Empire, París, Les Indes savantes.

Ribbe Ch. de (1890) Une grande Dame dans son ménage au temps de Louis XIV, d'après le journal de la comtesse de Rochefort, París, Palmé.

RochejaQuelin, Marquise de la (1984) Mémoires, París, Mercure de France (Le temps retrouvé).

Tholin, G. (I880) Le livre de raison des Daurée d'Agen (I49I-I67I), précédé d'une étude sur quelques livres de raison des anciennes familles de l'Agenais, Agen.

Traversier, M. (2017) Le journal d'une reine. Marie-Caroline de Naples dans l'Italie des Lumières, Ceyzérieu, Champ Vallon.

VInYoles, T. (2005) «La cotidianidad escrita por una mujer del siglo XV», en M. de Val González de la Pena (ed.), Mujer y cultura escrita, del mito al siglo XXI, Gijón, Ediciones TREA, p. II7-IzO.

ZARAGOZA, V. (20I8) «Impresión y legitimación de la escritura femenina en el siglo XVI. A propósito de un canto poético femenino interpolado (Valencia, I584)", en M. Morrás (ed.), Espacios en la Edad Media y el Renacimiento, Salamanca, SEMYR, p. 695-719. 